\title{
A constituição das creches nas universidades públicas estaduais paulistas: as relações de gênero e os direitos da mulher e da criança pequena - a busca por novas práticas
}

\begin{abstract}
Resumo: Este artigo apresenta um recorte de pesquisas realizadas no contexto das creches universitárias, apresentando o histórico de implementação das creches no interior das universidades estaduais paulistas e o estudo realizado focando as relações de gênero dentro de uma dessas creches. Apresentaremos uma breve contextualização acerca da trajetória de constituição da creche e sua ligação com o trabalho extra-domiciliar feminino, destacando que as raízes da Educação Infantil se ligam a questões externas as necessidades e direitos das crianças. Entraremos no histórico de constituição das creches universitárias aqui em questão, apresentando os meandros de seu processo de implementação destacando as questões legais que institucionalizaram as creches nas universidades públicas estaduais do Estado de São Paulo. Posteriormente, falaremos sobre as Pedagogias das Infâncias vivenciadas numa dessas creches universitárias focalizando o processo de construção dos estereótipos do feminino e masculino nas pedagogias desenvolvidas em seu interior.
\end{abstract}

Palavras-chave: Educação infantil. Creche universitária. Feminismo. Relações de Gênero.

\section{The creation of crèches in public universities in the state of São Paulo: gender relations and the rights of women and the young child - the search for new practices}

\begin{abstract}
This article presents a review of researches carried out in the context of university day care centers, presenting the history of the implementation of day care centers within the State universities of São Paulo and the study carried out focusing on gender relations within one of these day care centers. We will present a brief contextualization about the trajectory of the creation of the day care center and its connection with the extra-domiciliary work of women, emphasizing that the roots of Early Childhood Education relate to external issues the needs and rights of children. We will go into the history of the creation of the university day care centers in question, presenting the meanders of its implementation process highlighting the legal issues that institutionalized day care centers in state public universities in the State of São Paulo. Later, we will talk about the Pedagogies of the Infants experienced in one of these university nurseries focusing on the process of constructing the stereotypes of the feminine and masculine in the pedagogies developed in its interior.
\end{abstract}

Keywords: Early Childhood education. University day care center. Crèche. Feminism. Gender relations.

\footnotetext{
'Doutora em Educação (FE/ UNICAMP); Professora de Educação Infantil da Prefeitura Municipal de Campinas-SP. E-mail: supalmen@yahoo.com.br

2 Pedagoga (FE/UNICAMP); Professora de Educação Infantil na Rede Municipal de Ilhabela - SP. E-mail: viviancolella92@gmail.com
} 

ste artigo apresenta um recorte da dissertação de mestrado que aborda o processo de implementação de creches nas universidades públicas estaduais paulistas: USP, UNICAMP, UNESP tendo como foco da discussão o papel dos movimentos sociais, com destaque para o movimento de mulheres na luta pela implementação de creches no interior dessas universidades. O texto também se conecta com a pesquisa de graduação que aborda o estudo das relações de gênero na creche da Unicamp", realizada como trabalho de Conclusão de Curso de Pedagogia e que discute as relações de gênero no interior de uma das creches da Universidade de Campinas, não limitando o estudo as crianças, portanto, levando em consideração as relações das adultas, das professoras, das funcionárias, do espaço e da própria instituição ao analisar as práticas pedagógicas.

Ao falar na constituição das creches no interior das universidades públicas estaduais paulistas: USP, UNICAMP, UNESP cabe ressaltar que a trajetória dessa implementação nos remete a um histórico de luta liderado pelas mulheres, feministas, empregadas de empresas públicas e privadas, que reivindicavam por esse equipamento de educação e cuidado a seus filhos e filhas, principalmente a partir da década de 1970.

Retomando o histórico das creches no Brasil, vale destacar que nem sempre a creche foi defendida de forma generalizada; pelo contrário, sempre foi um campo de tensão e conflito por envolver questões referentes a padrões familiares centrados no patriarcado, pelos quais se atribuí a responsabilidade à mulher-mãe quanto à educação e cuidado da criança pequena. Assim, a constituição das creches foi objeto de controvérsias, porque colocava em discussão o papel materno versus as condições de vida da mulher pobre e trabalhadora.

De acordo com Kuhlmann Jr. (1998) no final do século XIX iniciou-se o processo de difusão das creches enquanto instituições modernas, sendo sua implantação junto às indústrias recomendadas, principalmente nos Congressos Internacionais de Assistência a Infância, pois tal medida era entendida como prioritária para a regularização das relações de trabalho, principalmente quanto ao trabalho feminino.

Nascimento (2001) pontua que a partir da segunda metade do século XX, na França, verificou-se o uso social da creche e do maternal através da expansão da utilização dessas instituições, inicialmente organizadas para atender a classe operária. A partir deste momento, tais instituições passam ser frequentadas por todas as classes sociais e por todas as categorias profissionais, "um fenômeno que foi denominado de exteriorização da guarda" (NASCIMENTO, 2001, p. 423). 
No Brasil, a creche também teve a finalidade de liberar a mão-de-obra da mãe pobre, porém, enquanto na Europa as creches surgem visando atender as necessidades das mulheres que trabalhavam no setor industrial, em nosso país essa demanda se dá inicialmente entre as trabalhadoras domésticas, já que aqui a industrialização encontrava-se em seus primórdios de desenvolvimento.

Com a inserção da mulher no mercado de trabalho, decorrente da expansão industrial e do amplo processo de urbanização, no início do século XX as instituições de Educação Infantil, especialmente as creches, passam a ser reivindicadas pelas mães trabalhadoras que necessitavam de um local para deixarem seus filhos e filhas durante a sua jornada de trabalho.

A Consolidação das Leis Trabalhistas - CLT, de 1943, no Brasil, passou a determinar que as empresas com mais de 30 mulheres trabalhadoras entre 16 a 40 anos de idade deviam ter um lugar para a guarda dos filhos e filhas de suas funcionárias durante o período de amamentação. De acordo com seu artigo 389, parágrafo $1^{\circ}$, a CLT estabelece a obrigatoriedade da empresa que se enquadre nesse perfil, de local apropriado que permita às empregadas guardar seus filhos durante o período de amamentação, considerado até os 6 meses de idade (CAMPOS, 1999, p.120).

Como pontua Fagundes (1997) essa legislação não trata do direito a creche nos locais de trabalho, pois fala somente sobre o direito da mulher trabalhadora a amamentar seu filho durante sua jornada de trabalho, sendo a amamentação permitida legalmente até os seis meses de idade da criança.

Contudo, somente pós Segunda Guerra Mundial que a educação e cuidado da criança pequena passam a ocorrer com maior ênfase fora de casa, ou seja, em equipamentos coletivos como creches, escolas maternais ou jardins-de-infância. Essa mudança no padrão de criação das crianças pequenas é decorrente das transformações ocorridas no mundo produtivo, das modificações nas relações de gênero e também das mudanças na concepção de criança pequena.

Dentro dessa ótica é que se dá o desprendimento da responsabilidade familiar para com a educação e cuidado da criança, deixando de ser encargo exclusivo da esfera privada e passando a se constituir dentro do capítulo das Políticas Públicas, ou seja, a família e o Estado passam a dividir a responsabilidade quanto ao bem-estar infantil, desempenhando ações complementares (ROSEMBERG, 1995).

De acordo com Merisse (1997), no que diz respeito especificamente ao atendimento à criança pequena, surge em São Paulo o Movimento de Luta por Creches, resultado das necessidades da mulher das camadas populares, que passa a ser cada vez mais exigida no trabalho fora do lar. Tal movimento também é fruto da ação de grupos de mulheres pertencentes às camadas médias da sociedade, com orientações feministas.

O movimento feminista colocava em destaque a questão dos cuidados e responsabilidades para com a infância, exigia modificações nos papéis sociais tradicionais do homem e da mulher, bem como na dinâmica das relações familiares. $\mathrm{O}$ movimento de Luta por Creches, sob influência do feminismo, apresentava suas reivindicações aos poderes públicos no contexto de uma luta por direitos sociais e de cidadania, modificando e acrescentando significados à creche, enquanto instituição. Esta começa a aparecer como um equipamento especializado para atender e educar a 
criança pequena que deveria ser compreendido como uma alternativa que poderia ser organizada de forma a ser apropriada e saudável para a criança, desejável à mulher e à família. A creche irá então aparecer como um serviço que é um direito da criança e da mulher, que oferece a possibilidade de opção por um atendimento complementar ao oferecido pela família, necessário e também desejável (MERISSE, 1997, p.48).

Somente a partir da segunda metade da década de 1970 e em decorrência da participação do movimento de mulheres é que ocorre no Brasil a expansão das creches. Nesta época, o Movimento de Luta por Creches na cidade de São Paulo desenvolveu forte pressão sobre o poder municipal visando a instalação das creches tendo como base do movimento as mulheres de operários, que por sua vez pretendiam uma vaga no mercado de trabalho. Para tanto precisavam de um local para deixar seus filhos e assim aumentarem a renda familiar.

Como as vagas nas creches das empresas eram limitadas aos filhos e filhas das operárias, as esposas dos operários buscavam outra saída a esse problema, lutar junto a Prefeitura pela expansão desse serviço (ROSEMBERG, 1984.).

Por meio desta breve contextualização histórica sobre a constituição da creche no Brasil vemos a importância dos movimentos sociais rumo à consolidação desse direito social que a mesma representa.

As creches surgem ligadas ao papel da mulher na sociedade, inicialmente pautadas nas reivindicações em prol da criação de locais de abrigo aos filhos e filhas das trabalhadoras e somente no final do século XX passam a ser consideradas como um direito da criança a esse espaço de educação e cuidado diferente de sua casa e passível a coletividade.

Tanto o Movimento de Luta por Creches quanto o Movimento Feminista evidenciam sua importância nesta luta social. Como retoma Sabbag (1997), neste contexto a creche aparece como conquista não só da mãe ou da família, mas como conquista social, produto de um processo interativo da coletividade.

Foi neste contexto de reivindicações dos movimentos sociais em prol as creches que as comunidades universitárias passaram a lutar pelo direito a assistência à criança durante sua jornada de trabalho.

Assim, mais precisamente em 1975, aconteceu na Universidade de São Paulo - USP um movimento de funcionárias e funcionários, alunos e professores em busca da creche no local de trabalho um movimento envolvendo homens e mulheres dentro de uma empresa pública, em seu local de trabalho, marcando o início da luta por creches no interior da universidade (ROSEMBERG, 1989).

No entanto, pensar a implantação de creches no interior de uma empresa pública, que é a Universidade significa resgatar as manifestações trabalhistas pautadas na CLT, lei trabalhista aprovada após o Movimento de 1930, período de amplas mudanças políticas, econômicas e sociais no Brasil.

A creche no local de trabalho possibilita a conciliação entre o horário de trabalho e o horário de funcionamento da creche, o que não é possível de modo geral quando tratamos de creches públicas municipais, conveniadas ou particulares. É dentro desse quadro que as creches no interior das 
universidades nasceram, visando atender a essa necessidade dos trabalhadores e trabalhadoras, ainda que inicialmente focalizasse apenas as salas de amamentação, como determina o referido texto da CLT.

Quando as empresas realizam convênios com outras creches, acabam por responder a uma necessidade legal, mas não a necessidade da mãe trabalhadora. Muitas vezes as vagas disponíveis em creches conveniadas nem são utilizadas devido a múltiplos fatores como: distância em relação ao local de trabalho, dificuldades de transporte, incompatibilidade entre o horário de funcionamento da creche com relação ao horário de trabalho da mãe ou pai. De acordo com Campos, Rosemberg e Ferreira (2001),

Todas as avaliações efetuadas, principalmente a partir dos anos 70, quando se iniciaram as mobilizações das mulheres em torno de seus direitos apontam para o não cumprimento da CLT e das Portarias subseqüentes pelas empresas brasileiras, dada a ineficiência de fiscalização e o baixo montante de multa prevista (CAMPOS; ROSEMBERG; FERREIRA, 2001, p. 63).

Nas universidades USP, UNICAMP, UNESP, a luta desencadeada na década de 1970 inicialmente pautava-se na CLT, a qual menciona apenas sobre a obrigatoriedade das salas de amamentação no local de trabalho, porém, a bandeira de luta se amplia para um local de educação e cuidado das crianças durante a jornada de trabalho de seus genitores, funcionárias e funcionários públicos.

Em 1982, em resposta aos longos anos de manifestações e reivindicações de seus funcionários e funcionárias em prol a creche no local de trabalho, o Governo do Estado de São Paulo implementou o Programa Centro de Convivência Infantil - CCI, obrigando as repartições e órgãos estaduais a instalar, inicialmente, creches nos locais de trabalho para os filhos e filhas de suas funcionárias.

A partir desse momento o Estado de São Paulo passou a contar com uma legislação própria na qual é dever do Estado prover o atendimento à infância em equipamentos de Educação Infantil, compartilhando essa tarefa com os demais empregadores, como determina a legislação trabalhista.

Assim, as salas de amamentação deram espaço às creches nas universidades, ou seja, um espaço de educação e cuidado à infância, atendendo as crianças para além do período de amamentação, em alguns casos, até os seis anos de idade.

\section{Creche: direito social da criança pequena}

No Brasil, as primeiras formas de assistência aos filhos das mulheres que trabalhavam fora de casa se deram no final do século XIX, por iniciativa de alguns empregadores com objetivos assistenciais e de atendimento médico. Entretanto, o atendimento a infância modificou-se ao longo dos anos por influência de fenômenos sociais e históricos, como a regulamentação do trabalho feminino e principalmente com a CLT - Consolidação das Leis Trabalhistas, em 1943.

Entretanto, como tentei mostrar ao longo deste artigo, a inserção das creches nos locais de trabalho, de acordo com a CLT é um direito apenas da mulher, prioritariamente durante o período de amamentação, excluindo-se dessa forma o direito do pai a vaga em creche para seu filho, atribuindo a tarefa de educar e cuidar dos filhos apenas a mulher. 
Em seus tempos iniciais, a creche estava vinculada às necessidades decorrentes do trabalho extradomiciliar da mulher e hoje, ainda que se considere esse aspecto, o atendimento à infância e sua educação extra-ambiente familiar é visto como um direito da criança, conquistado desde a promulgação da Constituição Brasileira de 1988 que passou a definir a educação infantil como "um direito da criança, um dever do Estado e uma opção da família".

Além da Constituição brasileira de 1988, hoje temos o Estatuto da Criança e do Adolescente, de 1990 e a Lei de Diretrizes e Bases da Educação no Brasil - LDB 9394/ 96, na qual a Educação Infantil passou a ser a primeira etapa da Educação Básica, legislações essas que reconhecem a criança como sujeito social de direitos (FARIA, 2005), portanto não mais objeto de tutela.

Autores que estudam a história da Educação Infantil como Bondioli (1998), Campos (1999), Kulhmann Jr. (2001), Rosemberg (1984; 1989; 1995), entre outros, nos mostram que as redes públicas de creches se originaram por motivações exteriores às necessidades das crianças estando as reais motivações ligadas às políticas de incentivo ao trabalho materno.

A proposta de creche voltou-se, até tempos recentes, àquela idéia de uma instituição voltada para a criança, filha das mães que trabalhassem fora apresentando-se como uma instituição com função compensatória a ausência familiar, portanto sem uma identidade própria. É neste contexto que surge o termo creche como substituta materna e sem um papel universal, já que se destina apenas a uma determinada clientela (ROSEMBERG, 1984; HADDAD, 1991).

Se em suas origens as instituições de educação infantil estavam mais próximas à mãe do que de seus filhos e filhas, o direito da criança de atendimento em creches passou a ser garantido a partir de 1988, com a promulgação da Constituição brasileira, não restringindo o direito à assistência unicamente à mulher.

Não é apenas a inserção da mulher no mercado de trabalho que explica a busca por creches e préescolas, mas também uma movimentação em torno da infância, revelando a preocupação quanto as suas necessidades educativas e de socialização, portanto, vendo-a sob uma nova ótica - portadora de especificidade.

Nas universidades públicas estaduais paulistas as creches constituem-se como um programa educativo e social de interesse público, embora não plenamente implementado nas universidades, já que nem todos os campi possuem creches em funcionamento.

Tais creches, além de cumprirem as tarefas de educação e cuidado das crianças de 0 a 3 anos, também respondem aos direitos de seus pais e suas mães que trabalham na universidade e que reivindicaram pela creche em seu local de trabalho, buscando através desse equipamento um espaço de educação e cuidado a seus filhos durante sua jornada de trabalho na universidade.

Apesar da consolidação da creche nas universidades públicas estaduais paulistas trazer em seu histórico uma longa trajetória de luta, no caso da USP iniciada na década de 1960 e no caso da UNICAMP e UNESP iniciada a partir da década de 1970, sua implementação acontecerá apenas na década de 1980, marcada pela luta das mulheres, feministas que buscavam pelos seus direitos a trabalhar, estudar e a se 
emancipar. Indissocialmente lutaram pelo direito de seus filhos e filhas à creche no interior das universidades, local de trabalho, portanto, lutaram por seus direitos.

As creches no interior das universidades representam a luta das mulheres pela consolidação de direitos, buscando na educação infantil o apoio para a emancipação e superação dos padrões patriarcais colonialistas que atribuem a mulher-mãe a responsabilidade pela educação e cuidado das crianças.

A criação do Programa CCI representa um marco na luta das mulheres, entretanto, cabe destacar que a temática creche no local de trabalho passou a compor a agenda política da universidade, tanto na USP, quanto UNICAMP e UNESP, devido aos movimentos das mulheres pela creche, reivindicando condições de exercer o direito a trabalhar fora de casa, de estudar e se emancipar.

A Educação Infantil, além de fazer parte das Políticas Educacionais, também faz parte da Política de Assistência aos trabalhadores homens e mulheres, como revela o histórico das creches no Brasil, ou seja, configura-se como Política Social. Dentro desse enfoque, as Políticas Sociais são formas de intervenção assumidas pelo poder público diante das necessidades e aspirações dos diferentes segmentos da sociedade.

Enfim, as creches implantadas nas universidades públicas paulistas têm em comum o fato de se originarem a partir de uma mesma motivação - a movimentação dos funcionários e funcionárias em busca de creches para seus filhos e filhas durante sua jornada de trabalho na universidade, estando o foco principalmente na figura da mulher que trabalha fora de casa, especificamente, da servidora pública estadual paulista.

\section{As relações de gênero na educação infantil - a creche universitária e as Pedagogias das Infâncias}

Pensando nas Pedagogias das Infâncias vivenciadas numa das creches universitárias aqui abordadas, a CAS - Creche da Área da Saúde da UNICAMP33, com crianças de 2 e 3 anos de idade, voltamos o olhar para o processo de construção dos estereótipos do feminino e masculino, ou seja, analisamos como tem se constituído as relações de gênero dentro desse espaço educacional.

As relações de gênero na educação infantil perpassam outros assuntos como a questão do binarismo e sexismo, nos quais os estereótipos do feminino e do masculino são impostos para as crianças desde bebês, diferenciando brinquedos e brincadeiras de meninas ou de meninos, limitando a construção social do gênero das pequenas e dos pequenos e perpetuando as opressões. Para lutar contra essas opressões, as discussões do Feminismo se fazem presentes, levando em conta que Pedagogia é uma profissão atrelada à história da mulher na sociedade e que a creche foi uma conquista do movimento feminista na década de 70 .

${ }^{3}$ A CAS - Creche da Área da Saúde da UNICAMP, atende crianças de 0 a 5 anos, contudo, a pesquisa acompanhou as turmas com crianças de 2 e 3 anos de idade. 
Não podemos perder de vista qual a concepção que temos em relação a criança. A criança deve ser reconhecida como protagonista da sua infância, no entanto, numa sociedade adultocêntrica ${ }^{4}$, acabam colocando-a erroneamente numa posição passiva em relação à cultura. As adultas e adultos que convivem com as crianças em todos os espaços, casa, creche, e outros, possuem uma posição de cuidado, preservação e, de certa forma, arrogância, por entender a criança enquanto um vir a ser, que precisa aprender sobre a vida e as coisas, sendo responsabilidade das adultas e adultos depositar o conhecimento nas pequenas e pequenos. Ou seja, a criança vive uma experiência escolarizante por toda sua infância, até mesmo fora das instituições educacionais.

Devemos pensar a:

Infância como experiência, devolvendo ao conceito uma multiplicidade que lhe foi retirada. [...] O que se quer dizer é que a experiência da infância não está vinculada unicamente à idade, à cronologia, a uma etapa psicológica ou a uma temporalidade linear, cumulativa e gradativa, já que ligada ao acontecimento; vincula-se à arte, à inventividade, ao intempestivo, ao ocasional, vincula-se, portanto, a uma des-idade (ABRAMOWICZ, 2011, p. 34).

Levando em conta os fatos históricos alinhados com os estudos e pesquisas da área de educação infantil e da criança enquanto um campo teórico, é possível entender que a pequena infância é a primeira fase da vida dos sujeitos, e é nesse começo de vida que nos construímos socialmente. Cada criança vive uma infância diferente, por isso, infâncias, nesse sentido, baseado nos estudos das infâncias, cada criança tem uma cultura própria.

A sociologia da infância chama esse processo de autoria social. A criança negra (única e universal) que nasce e inscreve em si o passado de sua raça, de sua história, já carrega suas inscrições, mas também traz em si uma criança (singular e múltipla), ou seja, a criança é, também, uma multiplicidade de tempo. Assim uma criança é ao mesmo tempo universal, individual e singular (ABRAMOWICZ, 2011, p. 20).

Sendo a criança singular e múltipla e sendo a infância uma categoria de análise, essa pequena infância não pode ser vista de forma isolada, devemos levar em conta outras categorias de análise, como classe, raça e etnia e a proposta principal desta pesquisa, o gênero.

Um dos primeiros estudiosos a utilizar o conceito de cultura infantil foi Florestan Fernandes em 1944, o qual define como elementos culturais construídos pelas crianças e entre elas no convívio em sociedade, com as adultas e adultos, caracterizados por sua natureza lúdica (FERNANDES, 2004).

A criança, ao mesmo tempo em que está inserida num contexto que reproduz as práticas da sociedade capitalista, baseadas nas relações desiguais de poder, de segregação e competição, enquanto produto e produtora de cultura, consegue subverter e contrariar as normas, fugir da lógica da sociedade como um todo, criando outras possibilidades, inventando, propondo, transgredindo, transformando e construindo outras formas de educação e sociedade.

Os pressupostos da sociologia da infância estão imbricados em outros estudos. A proposta de discutir gênero, por exemplo, perpassa pela ideia da infância enquanto uma construção e da existência de infâncias em contextos diferentes.

\footnotetext{
${ }^{4}$ Adultocentrismo é o mundo pensado pelos adultos para os adultos, deixando as especificidades das crianças de lado.
} 
Sendo assim, discutir gênero, se relaciona com outras questões, como (idade, classe, raça, etnia.), elementos estes importantes para pensar a infância como um todo de acordo com as pautas dos movimentos feministas.

Durante o período de abril de 2013 a janeiro de 2015 realizou-se a pesquisa ${ }^{5}$ intitulada "Entre Princesas e Piratas, um estudo das relações de gênero na creche da Unicamp", especificamente no interior da Creche da área da saúde da Unicamp. Essa a vivência na creche trouxe desconfortos em relação as questões de gênero, pois foram várias situações de opressão e imposição de estereótipos na vida das crianças presenciadas num ambiente em que as práticas pedagógicas deveriam questionar padrões sociais e proporcionar um ambiente acolhedor para a diversidade das crianças.

A partir desse acompanhamento do dia a dia da creche e dos questionamentos sobre as relações de gênero, que muitas vezes caiam num determinismo de gênero, podemos perceber a importância de aprofundar essas questões e esses assuntos que são pouco debatidos na Educação Infantil e na área educacional como um todo, para que os estereótipos de gênero não sejam limitantes na construção subjetiva das crianças.

A partir disso é imprescindível colocar a perspectiva das infâncias, já que as crianças também são vítimas dessa sociedade que impões estereótipos, as classifica e as limita. Estas práticas pedagógicas refletem o racismo e o machismo da sociedade e a essência de uma educação livre de opressões torna-se cada vez mais um desafio.

Partindo dessas e outras questões, esta pesquisa teve início com um levantamento bibliográfico das palavras chave: gênero, creche e culturas infantis, junto com algumas pesquisas do grupo GEPEDISC - Culturas Infantis da UNICAMP e textos de mulheres feministas e/ou negras. Um embasamento teórico da Sociologia da Infância deu o suporte necessário para discussão das infâncias, rompendo com a noção do estudo de uma criança genérica, levando em conta as diferentes infâncias e o protagonismo da criança.

Fazendo a análise dos registros realizados das vivências na creche as discussões acerca dos estereótipos de gênero e binarismo se fizeram presente. Tencionando a construir uma ideia de educação feminista e não-binária, questionando os papéis sociais impostos as mulheres, a relação delas com a educação e objetivando um olhar mais feminista para a educação.

O levantamento de episódios do diário de campo deu espaço para a discussão da reprodução ou transgressão de práticas sexistas e machistas experienciadas pelas crianças, levando em conta a interseccionalidade, as opressões de gênero cruzam com outros tipos de opressões, ou seja, é impossível discuti-las de formas isoladas. O feminismo interseccional entende existir uma relação que cria desigualdades básicas, opressões que estão subordinadas ao mesmo sistema.

\footnotetext{
${ }^{5}$ A pesquisa revela a construção das relações de gênero nos espaços educativos e a necessidade de conversarmos sobre essa temática, ainda renegada ou estereotipada.
} 


\section{Por uma Educação Feminista e Não-Binária}

Analisando e acompanhando as práticas de algumas professoras da creche foi possível perceber que muitas acabavam por incentivar os estereótipos do feminino nas meninas e do masculino nos meninos, e, ao mesmo tempo, impediam que as meninas tivessem um comportamento considerado masculino e que os meninos tivessem um comportamento considerado feminino, o que acaba sendo mais uma situação machista dentro da educação.

O machismo é um pensamento retrógrado que considera a mulher inferior ao homem e essa postura traz consequências em todos os âmbitos da vida de uma mulher e também de um homem, estabelecendo uma maneira padronizada e limitada de relacionamentos e posturas. Por séculos os homens possuem privilégios na sociedade, principalmente os homens brancos, héteros e cisgêneros.

Vários questionamentos foram surgindo ao longo da pesquisa:

- Como a mediação das professoras impede a construção livre do gênero da criança?

- Como a heteronormatividade é enfatizada?

- Em que momentos e como as professoras incentivam práticas sexistas?

- Como os estereótipos do feminino e masculino interferem nas relações das crianças? Como afetam as culturas infantis?

- Até que ponto a criança é transgressora das imposições dos estereótipos de gênero? Até que ponto as professoras também são vítimas do sistema que padroniza os gêneros?

- Será que as professoras tiveram acesso a discussões de gênero? Será que existe esse interesse?

- Em que momentos encontramos essas discussões dentro dos cursos de Pedagogia? Pedagogia é uma profissão considerada do gênero feminino? Por quê?

Uma educação feminista significa o fim da soberania masculina, onde os homens detêm o poder, a voz e ocupam cargos de mais prestígio na sociedade. A mulher teria seu espaço que é de direito, com salários iguais, funções iguais, afirmando que a profissão de professora não tem menos prestígio e que a mulher pode ter a profissão que quiser.

Sendo assim, o movimento feminista deve estar próximo das discussões dentro da Pedagogia, não só pelo motivo de que toda mulher deve ter acesso a esse debate para problematizarmos essas questões e nos livrarmos e superarmos essa 'subordinação', mas também por ter uma relação histórica, já que a creche foi uma conquista do movimento feminista em $1970^{6}$.

Joan Scott (1999), uma das primeiras feministas a problematizar o conceito de gênero explica que essa palavra começou a ser utilizada num sentido mais literal "como uma maneira de referir-se à organização social da relação entre os sexos" (SCOTT, 1999, p. 2). Na década de 80, as feministas começaram a usar a palavra "gênero" ao invés de "sexo", para enfatizar que as diferenças no comportamento de homens e mulheres não dependiam do sexo biológico, mas sim, eram definidos pelo gênero e ligados à cultura (PEDRO, 2005).

${ }^{6}$ No Brasil a garantia da educação de crianças de 0 a 6 anos em creches e pré-escolas pela Constituição aconteceu só em 1988 e sendo oito anos depois sistematizada na LDB/1996. (FARIA, 2005. p. 1022) 
Contudo, Judith Butler (2003) afirma que a ideia do gênero construído culturalmente pode ser tão limitante quanto o conceito ligado ao biológico, afirmando que o corpo acaba ficando numa posição passiva em relação à cultura, fundada num determinismo de gênero. Sendo assim, Butler (2003) cita a famosa frase da feminista Simone de Beauvoir a gente não nasce mulher, torna-se mulher e explica que mesmo que ela entenda o gênero enquanto uma construção "há um agente implicado em sua formulação" (BUTLER, 2003, p. 26).

O conceito gênero, mesmo discutido há anos por várias feministas, ainda não chega a um esgotamento da discussão e seus significados. É difícil defini-lo enquanto conceito, por ser algo tão fluente e que deve considerar suas variantes, como a cultura, o corpo, a próprio pessoa e o contexto social em que vivemos.

O gênero se torna, aliás, uma maneira de indicar as "construções sociais" - a criação inteiramente social das ideias sobre os papéis próprios aos homens e às mulheres. É uma maneira de se referir às origens exclusivamente sociais das identidades subjetivas dos homens e das mulheres. O gênero é, segundo essa definição, uma categoria social imposta sobre um corpo sexuado (SCOTT, 1999, p.7).

Ou seja, esses 'papéis próprios', inibem e punem qualquer comportamento que fuja do padrão determinado da relação sexo e gênero, e assim, todas as crianças são fadadas a crescer como a sociedade determina dentro do binarismo.

Os estereótipos definem as práticas dos sujeitos durante a vida, ou seja, os seres humanos são ensinados desde muito pequenos a seguirem certas regras sociais impostas culturalmente. A luta por uma educação feminista e não-binária é emergente para que nenhuma menina ou menino tenha suas vontades impedidas, seus sonhos apagados e sua vida definida a partir de seu sexo. Os estereótipos interferem nas escolhas de meninas e meninos desde muito cedo e por vivermos numa sociedade machista a menina é a que tem menos liberdade dentro dessa educação construída no sistema patriarcal.

Sendo assim, devemos propiciar uma educação feminista, emancipadora, que se preocupe em desconstruir os estereótipos, livre de julgamentos e determinações de gênero, para que esse processo de construção, que acontece ao longo da vida, não seja limitado logo na infância. Ao mesmo tempo em que as crianças resistem à sociedade machista, sexista e racista que impõem esses valores e que oprime por todos os lados, nós precisamos nos apropriar dessa resistência, lutar contra as imposições, racismos e acabar com essas expectativas que limitam o crescimento livre da criança, para que elas estabeleçam e construam suas próprias verdades e identidades.

[...] as crianças ainda não possuem práticas sexistas em suas brincadeiras e, portanto, não reproduzem o sexismo presente no mundo adulto. Esses meninos e meninas ainda não possuem o sexismo da forma como ele está disseminado na cultura construída pelo adulto: as crianças vão aprendendo a oposição e a hierarquia dos sexos ao longo do tempo que permanecem na escola (FINCO, 2003, p.95).

Analisando as observações na CAS a festa do Carnaval deve ser destacada. Ao longo da semana a professora já conversava com as crianças sobre a tão esperada sexta-feira do dia da fantasia e as crianças já expressavam suas vontades. 
Frida, menina negra de 3 anos, não via a hora de se vestir de Cinderela, a própria mãe comentou que estava tentando convencê-la a ir com outra fantasia, pois era um vestido muito elaborado e que limitava os movimentos, mas a menina insistia em colocá-lo. Entre os meninos, cada um viria de um super-herói diferente, até o caçador da Chapeuzinho Vermelho estava querendo aparecer e as outras meninas também desejavam ir de princesas (Diário de campo, 2014).

O momento da brincadeira da fantasia, sendo carnaval ou não, poderia ser uma oportunidade para desconstruir o sexismo, principalmente nas famílias, mas isso só seria possível se essa discussão sobre a importância da desconstrução dos estereótipos já estivesse presente na creche, entendendo que:

Os estereótipos podem levar a um prejulgamento, configurando-se como um preconceito relacionado a certos grupos e consequentemente a uma conduta que pode violar os direitos de outras pessoas baseados em critérios de raça, sexo, religião, gerando a discriminação. Os estereótipos são uma maneira de "biologizar" as características de um grupo. É uma generalização de características subjetivas para um determinado grupo, no caso dos estereótipos negativos, impondo-lhes o lugar de inferior, o lugar de incapaz (FINCO \& OLIVEIRA, 2011, p. 70).

A falta de questionamento sobre essa 'generalização de características subjetivas', faz com que a maioria das meninas deseje ir de princesas e da maioria dos meninos desejem ir de super-heróis. Essa lógica se faz presente devido maneira de 'biologizar as características', acreditando que são naturais essas diferenças entre as meninas e os meninos e acabam passando despercebidas pelo olhar de algumas professoras, que já estão acostumadas com essa divisão entre os sexos.

Não é natural e não faz parte do ser menina a vontade de ser princesa. As meninas têm como referência da maioria das histórias de princesas um comportamento totalmente submisso em relação às escolhas e preferências. Porém, as princesas têm tudo que desejam, desde um palácio, joias, vestidos, sapatos, até o parceiro mais bonito e o final feliz. Refletindo assim, mulheres fúteis, dependentes do pai ou marido, criando a imagem do "sexo frágil". Enquanto, o fato dos meninos serem mais agressivos e liderarem muitos momentos, também não é natural e biológico. Os meninos já estão acostumados a liderar desde pequenos, pois possuem referências das histórias dos reis, dos príncipes, ou dos vários outros papéis sociais masculinos das histórias e realidades, o pai, o irmão mais velho, o marido ou o patrão. A supremacia do sexo masculino não pode ser justificada por ser natural ou biológica, pois não é.

A criança já sofre uma violência até mesmo antes de nascer: na escolha de seu nome que tende a ser masculino ou feminino; na preferência de cores no quarto e roupas; até mesmo na escolha dos primeiros brinquedos e na forma de interação com aquela criança. Se existe um senso comum que a menina é mais delicada ela será tratada com muito mais cuidado e zelo do que um menino, que é considerado agitado e mais agressivo. Essas concepções enraizadas das adultas e adultos influenciam e são refletidas no comportamento das crianças.

As roupas e acessórios das crianças diferem não só pelas cores ditas de meninas ou de meninos, mas o tamanho, os detalhes e o material. As roupas dos meninos são mais confortáveis, dando mais liberdade para o movimento, enquanto das meninas, são justas e desconfortáveis, limitando muitos movimentos. 
Essa dicotomia do feminino e do masculino - o binarismo - coloca diferenças limitantes entre o masculino e o feminino e possui três parceiros principais na perpetuação do sistema patriarcal: o machismo, o androcentrismo e a misoginia. O machismo é marcado pela violência contra a mulher, física e psicológica, juntamente com o androcentrismo que se fundamenta na crença da superioridade masculina e inferioridade feminina e a misoginia que desconsidera e repulsa tudo que é relacionado à mulher e ao feminino.

A importância de uma educação não binária é justamente para lutar contra esse sistema patriarcal, machista, androcêntrico, misógino e também racista, que traz consequências sérias a todas as mulheres cisgênero, transgênero, transsexuais, as lésbicas, as bissexuais, a todas as travestis e também aos homens gays considerados "afeminados".

A partir do rompimento do binarismo, é possível dar espaços para a multiplicidade de gêneros e sexualidades que já existem, mas ainda vivem à margem da sociedade. Essa bipolarização é limitante e castradora, a partir do momento que julga errado um menino brincar de dançar ballet, pois é uma dança delicada, considerada feminina. Esse modelo de educação binária invade o universo da criança, limitando e colocando em caixinhas o que pode ou não pode de acordo com cada sexo.

\section{Considerações Finais}

Nas universidades públicas estaduais paulistas as creches constituem-se como um programa educativo e social de interesse público, que cumprem com a tarefa de educação e cuidado das crianças de 0 a 3 anos, ao mesmo tempo que respondem aos direitos de seus pais e suas mães que trabalham na universidade e que reivindicaram pela creche em seu local de trabalho.

A consolidação da creche nas universidades públicas estaduais paulistas traz em seu histórico uma longa trajetória de luta, contudo, sua implementação só acontece de fato na década de 1980, marcada pela luta das mulheres, feministas que buscavam pelos seus direitos a trabalhar, estudar e a se emancipar.

Como abordamos ao longo do texto, ao lutarem pelo direito de seus filhos e filhas à creche no interior das universidades, local de trabalho, indissocialmente essas mulheres lutaram por seus direitos, buscando na educação infantil o apoio para a emancipação e superação dos padrões patriarcais colonialistas que atribuem apenas a mulher-mãe a responsabilidade pela educação e cuidado das crianças.

Destacamos assim que a criação do Programa CCI representa um marco na luta das mulheres por creche no local de trabalho, contudo, se em suas origens as instituições de educação infantil estavam mais próximas à mãe do que de seus filhos e filhas, o direito da criança de atendimento em creches passou a ser garantido a partir de 1988, com a promulgação da Constituição brasileira, não restringindo o direito à assistência unicamente à mulher.

Através da pesquisa "Entre princesas e piratas: um estudo das relações de gênero em uma creche de universidade pública" foi possível perceber que por vivermos num contexto machista as docentes que atuam na atualidade numa das creches universitárias, conforme apresentamos ao longo do texto, também 
são vítimas das opressões de gênero, classe, raça, etnia, idade, entre outras e acabam por reproduzir essas desigualdades e opressões nas práticas pedagógicas desenvolvidas com as crianças.

Essa reprodução das opressões nas práticas pedagógicas é consequência do machismo e do racismo presente na sociedade de um modo geral. Devido a essa perpetuação das opressões dentro da nossa própria cultura, as crianças são oprimidas com as determinações binárias do gênero antes mesmo de nascer, também por conta de uma reprodução das opressões no interior da família. A criança ao entrar na creche tem a chance de encontrar um ambiente acolhedor que mostre diversas maneiras de se relacionar com o mundo e com as coisas e não só o binarismo e a heteronormatividade que são impostos socialmente, é papel da instituição construir um ambiente em que ela possa se construir livremente enquanto sujeito.

A construção desse ambiente acolhedor só pode ser feita de forma coletiva, é imprescindível que essa consciência das relações de gênero que limitam as visões e os comportamentos das crianças, seja não só das professoras, mas de todas as pessoas que estão inseridas na creche. Por acreditarmos que a criança chega à creche com uma forma de ver, ser e estar no mundo, pois ela não é uma folha em branco e nem apenas um vir-a-ser, as práticas pedagógicas devem ser voltadas para a desconstrução de atitudes, sentimentos e comportamentos que reproduzem práticas racistas, machistas, sexistas, heteronormativas e todas as formas de subordinação. Todavia, essa consciência por parte das docentes e demais pessoas na creche só seria possível com uma formação adequada, desde os cursos de Pedagogia até as formações continuadas.

As discussões de gênero não são pouco debatidas apenas na educação infantil, mas na nossa sociedade como um todo. A primeira infância acaba sendo vítima dessa ausência de discussão na sociedade e, consequentemente, na educação.

Esses espaços podem ser a base para desenvolver práticas que visam desconstruir os estereótipos de gênero e demais preconceitos. A partir dos episódios problematizados e com base nas teorias foi possível compreender que a luta contra as opressões tem que ser diária e vai além dos muros da creche. Além disso, não existe uma receita certa para as pedagogias, não existe um método infalível de combate às opressões, mas existe uma base que devemos levar em conta, como os direitos das crianças, que perpassa gênero, sexualidade, raça, etnia, classe, religião, idade, cultura, etc.

Essa visão que coloca o direito das crianças à frente e se propõe a desconstruir preconceitos, apresenta a possibilidade de uma educação para a liberdade. A produção das culturas infantis demonstra uma resistência das crianças contra esse sistema escolarizador e padronizador dos sujeitos.

Partindo das observações na creche podemos perceber o quanto as crianças são transgressoras dos padrões estabelecidos e impostos pela sociedade, não só em relação a questão de gênero, mas em relação a todo tipo de opressão. A criança deve ser protagonista da sua história e um dos papeis da creche é criar um ambiente em que ela possa construir sua identidade de modo que não reproduza as opressões ou se torne passiva diante delas. 
O entendimento das opressões de modo interseccional aponta para uma desconstrução e combate das opressões de forma geral. O Feminismo Interseccional coloca o racismo, o patriarcado, as opressões de classe e outros sistemas discriminatórios como criadores de desigualdades básicas, portanto, todos devem ser combatidos ao mesmo tempo e com a mesma força, não basta acabar com a opressão de classe, se ainda existe opressão de gênero e vice-versa, não basta acabar com o racismo, se ainda existe opressão de gênero e vice-versa.

É preciso pensar na formação continuada das profissionais da educação infantil, de forma a refletirem sobre as práticas pedagógicas tradicionais e as transformadoras das próprias práticas. Para isso a formação é o caminho para a revisão de concepções que fundamentam as ações. É preciso recuperar a essência feminista que originou as creches nas universidades e resgatar a consciência feminista em seu interior. Sendo assim, um conjunto de ações se faz necessário e se o começo da pesquisa se deu com perguntas que questionavam as práticas pedagógicas de algumas professoras que atuam na CAS, após as observações, intervenções e bibliografia, é possível problematizar se as práticas das professoras seriam apenas um passo contra essas opressões interseccionadas observadas na creche.

São pequenas intervenções que junto com uma formação continuada para as professoras, com mais espaços que possibilite troca de experiências entre professoras, funcionárias, famílias e comunidade em geral, com veículos de informação que funcionem e fomentem a reflexão, com brinquedos, livros, desenhos e filmes que não sejam machistas, sexistas e racistas, todo esse conjunto de ações pode facilitar na construção de um ambiente favorável para desconstruir os preconceitos.

A creche também é responsável pelo combate às opressões e deve fazer parte das políticas públicas, se posicionando a favor de uma educação pública, gratuita, de qualidade, de acesso a todas e todos.

Que mais estudos sobre as relações de gênero na creche nos subsidiem a sonhar com uma educação feminista apontando para novas pesquisas que discutam os temas relacionados a gênero, como o feminismo interseccional junto com os estudos das infâncias.

A nossa luta é todo dia, contra o racismo, o machismo, a LGBTfobia, enfim, contra todo tipo de discriminação e por práticas educativas inclusivas.

\section{Referências}

BONDIOLI, Anna. Introdução - As funções sociais da creche: um serviço para quem? In: BONDIOLI, Anna; MANTOVANI, Susanna (org.). Manual de educação Infantil: de 0-3 anos - uma abordagem reflexiva. Porto Alegre: Artmed, 1998. p. 13-37.

BUTLER, Judith. Capítulo 1: Sujeitos do sexo/gênero/desejo. In: Problemas de gênero. Rio de Janeiro: Civilização Brasileira, 2003. p 17 - 37. 
CAMPOS, Maria M. A mulher, a criança e seus direitos. Cadernos de Pesquisa, FCC, São Paulo, nº 106, p.117-127, março 1999.

CAMPOS, Maria M.; ROSEMBERG, Fúlvia; FERREIRA, Isabel M. Creches e Pré-escolas no Brasil. São Paulo: Cortez; Fundação Carlos Chagas, 1993.

CRAIDY, Carmem M. A política de educação infantil no contexto da política da infância no Brasil. Anais I Simpósio de Educação Infantil. Brasília, MEC, 1994. p.18-21.

ESTEVES, Vivian Colella. Entre princesas e piratas: um estudo das relações de gênero na creche da Unicamp. Campinas, S.P, 2016. Trabalho de Conclusão de Curso de Pedagogia. Faculdade de Educação, UNICAMP.

FAGUNDES, Magali R. A creche no trabalho..., ... o trabalho na creche: um estudo sobre o Centro de Convivência Infantil da UNICAMP: trajetória e perspectivas. Campinas, SP, 1997. Dissertação (Mestrado). Faculdade de Educação, UNICAMP.

FARIA, Ana Lúcia G. As Políticas de regulação, pesquisa e pedagogia na educação infantil, primeira etapa da educação básica. Educação e Sociedade, n. 92, p.1013 - 1038, Edição Especial, 2005.

FINCO, Daniela. Relações de gênero nas brincadeiras de meninos e meninas na educação infantil. ProPosições. v.14, n.3 (42) - set./dez. 2003.

FINCO, D. \& FARIA, A. L. G. (Orgs.). Sociologia da infância no Brasil. Campinas, SP: Autores Associados, 2011. Coleção polêmicas do nosso tempo.

FERNANDES, Florestan. As “Trocinhas do Bom Retiro: contribuições ao estudo folclórico e sociológico da cultura e dos grupos infantis. Pro-Posições. v.15, n.1 (43) - jan,/abr. 2004.

HADDAD, Lenira. A creche em busca de identidade. São Paulo: Loyola, 1991.

KUHLMANN JR., Moysés. Infância e Educação Infantil - uma abordagem histórica. Porto Alegre: Mediação, 1998.

MERISSE, Antonio. As origens das instituições de atendimento à criança: o caso das creches. In: MERISSE, A. (et. al.) Lugares da infância: reflexões sobre a história da criança na fábrica, creche e orfanato. São Paulo: Arte \& Ciência, 1997. p. 25-51. 
NASCIMENTO, Maria Evelyna P. Do adulto em miniatura à criança como sujeito de direitos: a construção de políticas de educação para a criança de tenra idade na França. Campinas, SP, 2001. Tese (Doutorado). Faculdade de Educação, UNICAMP.

PALMEN, Sueli H. C. A implementação de creches nas universidades públicas estaduais paulistas: USP, UNICAMP, UNESP. Campinas, S.P, 2005. Dissertação (Mestrado). Faculdade de Educação, UNICAMP.

PEDRO, Joana Maria. Traduzindo o debate: o uso da categoria gênero na pesquisa histórica. História, São Paulo, v.24, N.1, P.77-98, 2005.

PILOTTI, Francisco; RIZZINI, Irene (org.). A arte de governar crianças. A história das Políticas Sociais, da Legislação e da Assistência à infância no Brasil. Rio de Janeiro: Instituto Interamericano Del Niño, Universidade Santa Úrsula, 1995.

PRICOCO, Adalgisa. Nido aziendale e "venti di novità". Bambini, Anno XXI, supplemento al n.2 (Dossier - L'esperienza CGM nei nidi aziendali), p. 30-38, febbraio 2004.

ROSEMBERG, Fúlvia. O movimento de mulheres e a abertura política no Brasil: o caso da creche. Cadernos de Pesquisa, (51), p. 90-103, 1984.

ROSEMBERG, Fúlvia (org.). Creche. São Paulo: Cortez, Fundação Carlos Chagas, 1989

A criação dos filhos pequenos: tendências e ambigüidades contemporâneas. In: RIBEIRO \& RIBEIRO. Família em processos contemporâneos: inovações culturais na sociedade brasileira. São Paulo: Loyola, 1995. p. 167-190.

SABBAG, Sandra Papesky. Creches - surgimento, evolução e perspectivas, Revista Presença Pedagógica, Belo Horizonte: MG, $\mathrm{n}^{\mathrm{o}}$ 14, mar/abr. $1997 . \quad$ Disponível em: $<$ http://www.editoradimensao.com.br/revistas/revista14 trecho.htm $>$ Acesso em: 10 de abril de 2005.

SÃO PAULO. Governo do Estado. Fundo de Assistência Social do Palácio do Governo. Programa Centro de Convivência Infantil; Dossiê - 1847, FCC - Fundação Carlos Chagas.

SÃO PAULO. Governo do Estado. Fundo de Assistência Social do Palácio do Governo. Programa Centro de Convivência Infantil; Relatório/ Dossiê - 1848, FCC - Fundação Carlos Chagas.

SCOTT, Joan. Gênero: uma categoria útil para análise histórica. In: Acessado em: 10 de mar. 2014. 
